\title{
Synthetic biologists and conservationists open talks
}

\section{But worries persist about unintended consequences of tinkering with nature.}

\section{BY EWEN CALLAWAY}

A ustralian scientists made headlines last month when they revealed that they were close to cloning a frog, Rheobatrachus silus, last seen in the wild three decades ago. If they succeed, it may take another emerging technology to keep that frog alive.

Synthetic biology aims to endow organisms with new sets of genes and new abilities. Along with cloning, it has been portrayed in the press as a hubristic push to do fantastical things: bring back woolly mammoths or resurrect the passenger pigeons that darkened the skies of North America before they were eradicated by nineteenth-century settlers.

But at a first-of-its-kind meeting, held on 9-11 April at the University of Cambridge, UK, leading conservationists and synthetic biologists discussed how the technology could be applied in less fanciful ways to benefit the planet: to produce heat-tolerant coral reefs, pollution-sensing soil microbes and ruminant gut microbes that don't belch methane. Also on the list were ways to help frogs to overcome chytridiomycosis, the fungal disease threatening amphibians worldwide that is thought to have contributed to the extinction of $R$. silus.

The discussions took place against a background of mutual wariness, however. One synthetic biologist told the conference that he felt as though he were being treated like an irresponsible teenager who might accidentally wreck the planet. And conservationists bristled when a synthetic biologist announced that those in favour of the technology would win simply because they are younger than those who are against it. (He apologized the next day.) Kent Redford, a consultant for the Wildlife Conservation Society in New York and organizer of the meeting, made repeated calls for comity, plying attendees with free wine.

Such bickering is a sign that the fields are beginning to engage, says Drew Endy of Stanford University, California, who is widely seen as a co-founder of the synthetic-biology field. "How are we going to explore the notion that we

ONATURE.COM

For more on the issues of synthetic biology, see. go.nature.com/pls4ka

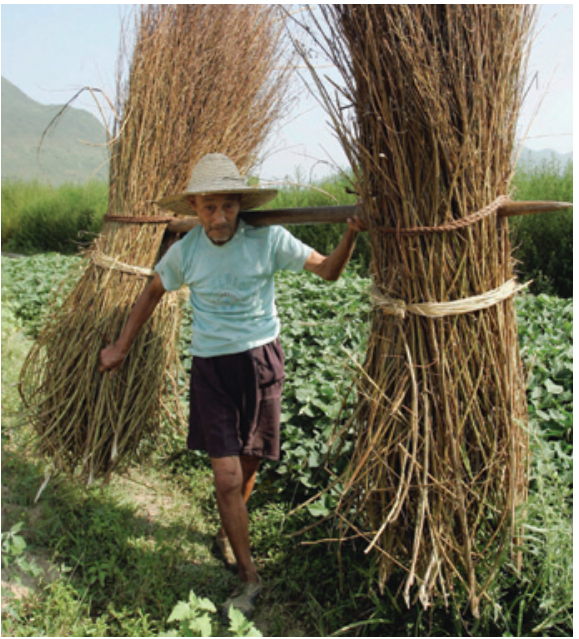

Sweet wormwood could be complemented by yeast as a source of the antimalarial artemisinin.

isn't going to figure it out by itself," he says.

Producing fuels, foods and medicines with microbes is the cutting edge of the field, stresses Richard Kitney, a synthetic biologist at Imperial College London. "We're not trying to produce woolly mammoths," he says.

\section{SOIL SAVER}

As an example of what the field can offer conservation, Kitney cites an undergraduate project he supervised that was presented at the 2011 International Genetically Engineered Machine competition, a kind of syntheticbiology science fair. Christopher Schoene, now at the University of Oxford, UK, and his team engineered Escherichia coli so that the bacterium would migrate into plant roots and produce the growth hormone auxin. In greenhouse tests, roots of cress plants that contained the engineered bacterium grew longer than those without, and the soil retained more water. Such a bacterium might help to combat desertification - the degradation of fertile land into desert when soil nutrients are lost.

But synthetic biology worries some observers, who fear what might happen if genes or organisms escape from their intended niches. Paul Falkowski, a geomicrobiologist at Rutgers University in New Brunswick, New Jersey, sees value in microbes that can turn carbon dioxide into fuel or make fertilizers from atmospheric nitrogen, but he worries that industrial-scale production could have drastic consequences, such as the inadvertent production of greenhouse gases. "I am rather amazed at the naivety of synthetic biologists at the way the world works," he says.

Many attendees also expressed nervousness about the potential of synthetic biology to influence land-use patterns. Microbes that reduce greenhouse-gas levels might lessen the pressure on governments to maintain rainforests, they said. Technologies that make marginal lands more productive could turn undeveloped land into single-crop farms.

Such shifts are already beginning to occur. A project begun by Jay Keasling, a synthetic biologist at the Lawrence Berkeley National Laboratory in California, coaxed yeast to produce the antimalarial drug artemesinin at industrial levels (see Nature 494, 160-161;2013). Much of the drug currently comes from cultivation of sweet wormwood (Artemisia annua), but Keasling believes that synthetic sources will eventually force A. annua growers in China and elsewhere to cultivate other crops. "I don't make the decision about what gets produced," says Keasling, whose company, Amyris in Emeryville, California, aims to produce industrial products with engineered microbes. "The marketplace decides. What I do is provide more options."

Concerns could be mitigated by designing ways to limit the spread of synthetic microbes. Schoene's team, for example, added a genetic safeguard to its E. coli that stops other microbes from acquiring the auxin-producing gene. "If [safeguards] are being developed with as much creativity as other technologies, that would reassure me a lot," says Stephen Palumbi, a marine biologist at Stanford University's Hopkins Marine Station in Pacific Grove, California.

Bill Sutherland, a conservation biologist at the University of Cambridge, agrees that his colleagues need to take synthetic biology seriously. But he says that a small poll he took at the meeting shows that the gulf between the two disciplines is not so wide. Both agree that more-efficient use of natural resources could be an important boon from synthetic biology. Both worry about the potential for synthetic organisms to harm natural ecosystems.

One issue that neither group was excited or very bothered about: restoring long-dead species. "It's a lot of fun," Sutherland says, "but it's not going to save the world." - 